\title{
The longitudinal relationship between immune cell profiles and frailty in patients with breast cancer receiving chemotherapy
}

Nikesha Gilmore ${ }^{1 *}$ D , Supriya Mohile ${ }^{2}$, Lianlian Lei ${ }^{3}$, Eva Culakova $^{1}$, Mostafa Mohamed $^{2}$, Allison Magnuson², Kah Poh Loh', Ronald Maggiore ${ }^{2}$, Elizabeth Belcher ${ }^{1}$, Alison Conlin ${ }^{4}$, Lora Weiselberg ${ }^{5}$, Mary Ontko ${ }^{6}$ and Michelle Janelsins ${ }^{1 *}$

\begin{abstract}
Background: Frailty is associated with an increased risk of chemotherapy toxicity. Cellular markers of inflammation can help identify patients with frailty characteristics. However, the role of cellular markers of inflammation in identifying patients at risk of developing chemotherapy-induced frailty and their clinical utility are not fully understood.

Methods: This study was a secondary analysis of a large nationwide cohort study of women with stage I-IIIC breast cancer ( $n=581$, mean age 53.4; range 22-81). Measures were completed pre-chemotherapy (T1), post-

chemotherapy (T2), and 6 months post-chemotherapy (T3). Frailty was assessed at all three time points using a modified Fried score consisting of four self-reported measures (weakness, exhaustion, physical activity, and walking speed; 0-4, 1 point for each). Immune cell counts as well as neutrophil to lymphocyte ratio (NLR) and lymphocyte to monocyte ratio (LMR) were obtained at $\mathrm{T} 1$ and $\mathrm{T} 2$ time points. Separate linear regressions were used to evaluate the associations of (1) cell counts at T1 with frailty at $\mathrm{T} 1, \mathrm{~T} 2$, and $\mathrm{T} 3$ and (2) change in cell counts (T2-T1) with frailty at T2 and T3. We controlled for relevant covariates and frailty at the T1 time point.
\end{abstract}

Results: From $\mathrm{T} 1$ to $\mathrm{T} 2$, the mean frailty score increased (1.3 vs 2.0; $p<0.01$ ) and returned to $\mathrm{T} 1$ levels by the $\mathrm{T3}$ time point (1.3 vs $1.3 ; p=0.85$ ). At the T1 time point, there was a positive association between cellular markers of inflammation and frailty: WBC $(\beta=0.04 ; p<0.05)$, neutrophils $(\beta=0.04 ; p<0.05)$, and NLR $(\beta=0.04 ; p<0.01)$. From T1 to T2, a greater increase in cellular markers of inflammation was associated with frailty at T2 (WBC: $\beta=0.02, p<$ 0.05 ; neutrophils: $\beta=0.03, p<0.05 ;$ NLR: $\beta=0.03 ; p<0.01$ ). These associations remained significant after controlling for the receipt of growth factors with chemotherapy and the time between when laboratory data was provided and the start or end of chemotherapy.

Conclusions: In patients with breast cancer undergoing chemotherapy, cellular markers of inflammation are associated with frailty. Immune cell counts may help clinicians identify patients at risk of frailty during chemotherapy.

(Continued on next page)

\footnotetext{
*Correspondence: nikesha_gilmore@URMC.rochester.edu;

michelle_janelsins@URMC.rochester.edu

${ }^{1}$ Cancer Control, University of Rochester School of Medicine and Dentistry, Rochester, New York, USA

Full list of author information is available at the end of the article
}

(c) The Author(s). 2021 Open Access This article is licensed under a Creative Commons Attribution 4.0 International License, which permits use, sharing, adaptation, distribution and reproduction in any medium or format, as long as you give appropriate credit to the original author(s) and the source, provide a link to the Creative Commons licence, and indicate if changes were made. The images or other third party material in this article are included in the article's Creative Commons licence, unless indicated otherwise in a credit line to the material. If material is not included in the article's Creative Commons licence and your intended use is not permitted by statutory regulation or exceeds the permitted use, you will need to obtain permission directly from the copyright holder. To view a copy of this licence, visit http://creativecommons.org/licenses/by/4.0/ The Creative Commons Public Domain Dedication waiver (http://creativecommons.org/publicdomain/zero/1.0/) applies to the data made available in this article, unless otherwise stated in a credit line to the data. 
(Continued from previous page)

Trial registration: ClinicalTrials.gov, NCT01382082

Keywords: Frailty, Chemotherapy, Inflammation, Breast cancer, Immune cell profiles, Cellular markers of inflammation

\section{Background}

Breast cancer is one of the most commonly diagnosed cancers in women in the USA [1]. Fortunately, mortality rates due to breast cancer have been on a steady decline over the last decade [1]. Despite evidence that adjuvant chemotherapy for breast cancer reduces the risk of disease recurrence, these treatments have concomitant consequences and may cause side effects that are associated with frailty [2]. Frailty categorizes an individual's physiologic reserves and is a significant problem for patients with breast cancer as well as survivors of cancer and particularly for long-term survivors of pediatric malignancies [3]. Fried and colleagues defined frailty phenotypically as a clinical syndrome consisting of three or more of the following: weakness, fatigue, low physical activity, slow walking speed, and unintentional weight loss [4]. The association of frailty with a variety of adverse outcomes has been well established. Frailty is associated with an increased vulnerability to stressors, impaired cognitive function, and increased risk of disability and mortality [4-7]. Furthermore, it has been demonstrated that frail women with breast cancer have an increased risk of chemotherapy toxicity, reduced chemotherapy tolerance, and lower health-related quality of life $[8,9]$. Given the adverse effects of frailty on outcomes in patients with cancer, understanding the factors that contribute to frailty as well as determining which biological markers can identify the women with breast cancer who are at increased risk of chemotherapyinduced frailty and may improve clinical outcomes.

Chronic inflammation has been shown to contribute to the development of frailty [10]. Leukocytes (white blood cells; WBC), an essential part of the immune system, consist of granulocytes (neutrophils, basophils, and eosinophils), lymphocytes ( $\mathrm{T}, \mathrm{B}$, and NK cells), and monocytes (macrophages and dendritic cells). An increase in the relative numbers of different types of leukocytes is an indicator of systemic inflammation. Although there are more precise ways to measure inflammation, such as the use of biochemical markers, these measures are time consuming, expensive, and not typically part of routine clinical practice. Thus, total and differential counts of cellular markers of inflammation such as neutrophils, lymphocytes, monocytes, neutrophil to lymphocyte ratio (NLR), and lymphocyte to monocyte to ratio (LMR) are commonly used because these are frequently measured as part of clinical care [11, 12].
These cellular markers of inflammation are elevated in frail community-dwelling older women [13]. Specifically, increased counts of circulating total WBC, neutrophils, and monocytes have been shown to be associated with frailty $[13,14]$. These associations have also been demonstrated in patients with cancer; a high NLR is positively associated with frailty and is also associated with reduced physical and functional outcomes prior to starting cancer treatment [15]. Cellular markers of inflammation have also been reported to have robust prognostic value in a variety of cancers. For instance, increased total WBC, neutrophils, and monocytes and decreased lymphocytes are associated with increased mortality [13, 16-21], and elevated NLR and lower LMR are predictive of poor prognosis [12, 22, 23].

Taken together, these studies have improved our understanding of the biochemical and cellular markers of inflammation that are associated with frailty in community-dwelling adults as well as in patients with cancer. However, the longitudinal relationship between total and differential leukocytes, in particular neutrophils, lymphocytes, monocytes, NLR, and LMR, prior to receiving chemotherapy with acute and persistent frailty after chemotherapy, has not yet been described. To address these questions in patients with breast cancer receiving chemotherapy, we investigated whether prechemotherapy levels of these cellular markers of inflammation as well as their change with chemotherapy were associated with post-chemotherapy frailty and frailty that persists up to 6 months after the completion of chemotherapy. We hypothesized that patients with a heightened inflammatory state, as evidenced by an imbalance in their cellular markers of inflammation prior to receiving chemotherapy, and those with the greatest increase in their cellular markers of inflammation with chemotherapy would be more likely to develop chemotherapyinduced frailty.

\section{Methods \\ Study design}

We conducted a secondary analysis of data from a large nationwide prospective, cohort study that has been previously published [24, 25]. We investigated the association of cellular markers of inflammation with frailty in female patients with breast cancer. Patients were recruited throughout the USA from the University of Rochester Cancer Center (URCC) National Cancer 
Institute (NCI) Community Oncology Research Program (NCORP) Community Affiliates. The primary study was a longitudinal cohort study aimed to determine the effects of chemotherapy on cognition (URCC 10055; ClinicalTrials.gov identifier NCT01382082) and enrolled participants with breast cancer and paired controls from 2011 to 2013 [24, 25]. Measures were completed within 7 days of the first cycle of chemotherapy (pre-chemotherapy), within 4 weeks of the last chemotherapy cycle (post-chemotherapy), and 6 months after the last chemotherapy cycle. For this study, we included all patients with breast cancer with available total and differential leukocyte data (Fig. 1). Institutional review boards at the URCC NCORP Research Base and at each of the NCORP Community Affiliates approved the study. All participants provided informed consent before completing study requirements.

\section{Study participants}

In the primary study, patients were included if they were (1) female, (2) diagnosed with invasive breast cancer (stage I-IIIC) and scheduled to begin a course of adjuvant or neoadjuvant chemotherapy, (3) chemotherapy naïve, (4) expected to live greater than 10 months, (5) able to speak and read English, and (6) able to provide written informed consent. Patients were excluded if they were (1) hospitalized at the time of study or had been hospitalized within the last year for a psychiatric illness, (2) diagnosed with a neurodegenerative disease, (3) had any primary central nervous system disease, (4) scheduled to receive concurrent radiation treatment while receiving chemotherapy, (5) have (or have had) metastatic disease and pregnant, and/or (6) colorblind [24].

\section{Measures \\ Frailty}

Our primary outcome measures were frailty determined pre-chemotherapy (within 7 days of the first cycle of chemotherapy), post-chemotherapy (within 4 weeks of the last chemotherapy cycle), and 6-month postchemotherapy time points. Fried's frailty score was used to assess frailty in this cohort. Fried's frailty is a validated measure used to identify frail individuals by assessing five criteria: weakness, exhaustion, walking speed, physical activity, and unintentional weight loss. The primary study (URCC10055) did not include measures to assess unintentional weight loss. As a result, we used a modified version of Fried's frailty score using four available criteria (weakness, exhaustion, walking speed, and physical activity) as has been previously reported [26, 27]. The four criteria were assessed using self-reported validated measures as follows: (1) weakness ( $\geq 4$ on scale of 1-10 on Symptom Inventory (SI)); (2) exhaustion ( $\geq 4$ on scale of $1-10$ on SI); (3) walking speed $(<2 \mathrm{mph}$ on Aerobic Center Longitudinal Study Physical Activity Questionnaire (ACLS)), and physical activity (<150 min/ week on ACLS) [26-28]. For each criterion, participants received a score of 1 if they met the cut-off for that criterion; otherwise, they received a score of 0 . Thus,

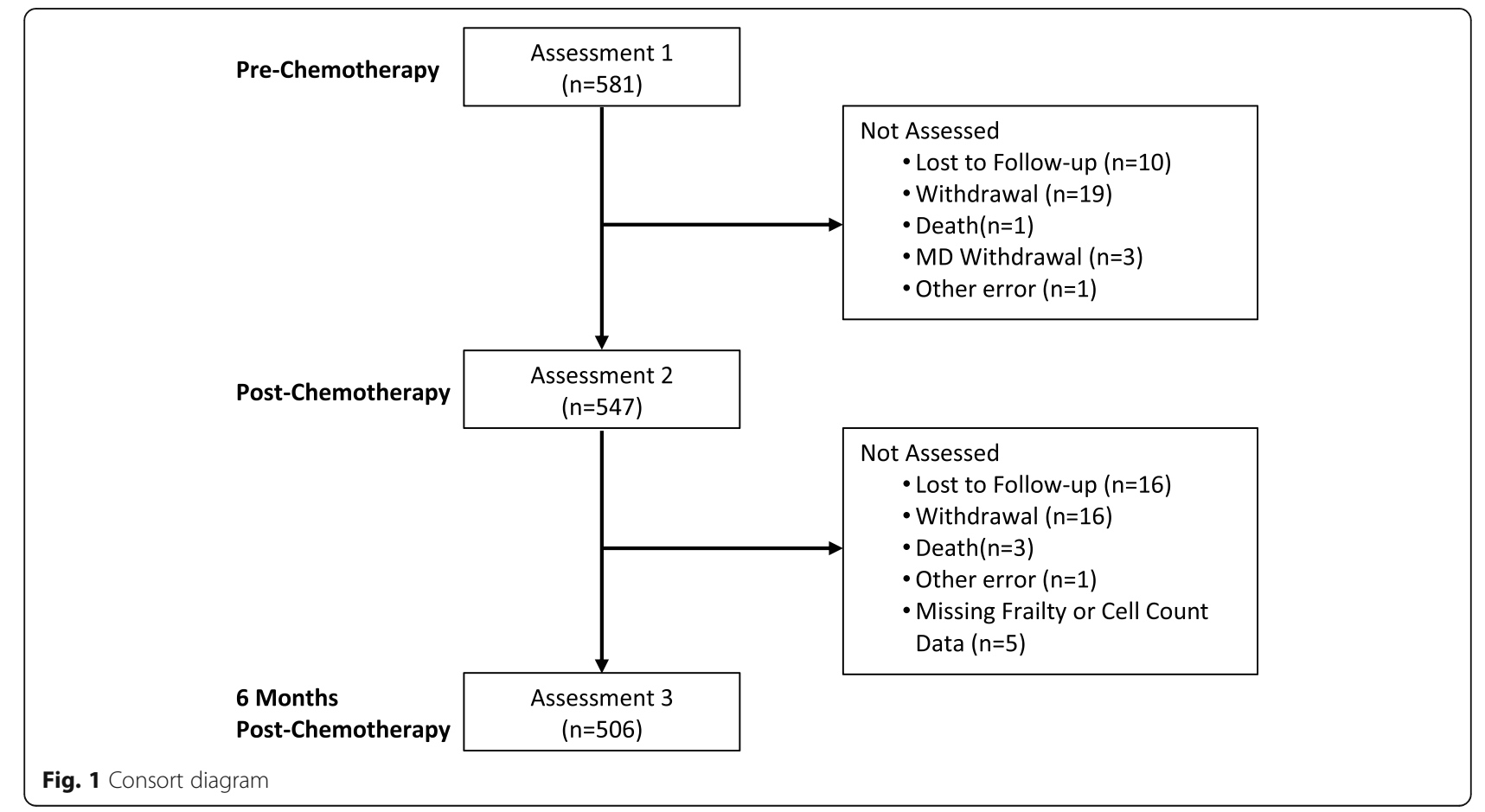


participants received a frailty score ranging from 0 to 4 , with a score of 0 having the least frailty characteristics and four having the most frailty characteristics.

\section{Immune cell composition}

Laboratory data taken from the medical record were also obtained at the pre-chemotherapy and postchemotherapy time points. Pre-chemotherapy laboratory data were obtained on average $12.2(\mathrm{SD}=17.8)$ days before the first day of chemotherapy (with approximately $70 \%$ of laboratory data obtained within 14 days of the start of chemotherapy). Post-chemotherapy laboratory data were obtained on average 18.4 $(\mathrm{SD}=24.3)$ days after the last day of chemotherapy (with approximately $70 \%$ of laboratory data obtained within 21 days of the end of chemotherapy). Total WBC, neutrophils, lymphocytes, monocytes, and platelets were reported in $10^{3}$ cells $/ \mu \mathrm{L}$ and extracted from the medical records by study staff. Hemoglobin and albumin reported in grams per deciliter and hematocrit reported in percentages were also extracted from the medical records. A physician with board certifications in hematology and geriatric medicine reviewed all lab values to confirm reporting accuracy. Any discrepancies were clarified by communityaffiliated sites according to standard operating procedures. NLR and LMR were calculated. Neutrophils, lymphocytes, monocytes, NLR, LMR, and total WBC were assessed as our independent variables.

\section{Statistical analyses}

Participants self-reported age, race, education, and marital status. Age was categorized into $<50,50-64$, and $\geq$ 65 years. Other demographic variables were dichotomized accordingly: race (white vs non-white), education (high school or below vs some college or above), and marital status (married/long-term relationship vs others). Cancer stage, treatment type (adjuvant vs neoadjuvant), type of chemotherapy (anthracycline vs nonanthracycline), growth factor treatment (yes vs no), date that the complete blood count $(\mathrm{CBC})$ was obtained, and the start and end dates of chemotherapy were extracted from the medical records. Descriptive statistics were used to summarize the baseline characteristics of the sample.

Chi-square tests were used to compare differences in the components of frailty and frailty score between prechemotherapy and post-chemotherapy and between prechemotherapy and 6 months post-chemotherapy. Paired $T$ tests were used to compare the differences in neutrophils, lymphocytes, monocytes, NLR, LMR, total WBC, hematocrit, hemoglobin, albumin, and platelets between pre-chemotherapy and post-chemotherapy and between pre-chemotherapy and 6 months post-chemotherapy. Separate linear regression models were used to evaluate the relationships between (1) pre-chemotherapy cellular markers of inflammation (neutrophils, lymphocytes, monocytes, NLR, LMR, and total WBC) and prechemotherapy frailty; (2) pre-chemotherapy cellular markers of inflammation and post-chemotherapy frailty; (3) pre-chemotherapy cellular markers of inflammation and 6-month post-chemotherapy frailty; (4) change in cellular markers of inflammation (from prechemotherapy to post-chemotherapy) and postchemotherapy frailty; and (5) change in cellular markers of inflammation (from pre-chemotherapy to postchemotherapy) and 6 months post-chemotherapy. In each model, we controlled for baseline frailty, age, race, marital status, and education.

Given that chemotherapy reduces individuals' total WBC, hematopoietic growth factors are commonly given to patients with breast cancer undergoing chemotherapy as supportive care medications to assist in the production of new WBC to prevent infection. Due to the effect of growth factors (given 24-48 h after chemotherapy infusion) on the WBC counts, we wanted to rule out the influence of growth factors on the association of cellular markers of inflammation with frailty after the completion of chemotherapy. Thus, all multivariate analyses were repeated in the subset of patients who received growth factors support after chemotherapy infusions. We did not evaluate the influence of the timing of steroids on the association of cellular markers of inflammation with frailty at the pre-chemotherapy time point as steroids are routinely given within $30 \mathrm{~min}$ of the chemotherapy infusion (i.e., after laboratories are obtained).

Furthermore, given that the timing of the date that the laboratory data was variable within the allotted study time point windows and the start and end dates of chemotherapy could affect immune cell counts as well as their ratios, we wanted to determine the influence (if any) of the timing of the cell counts and the start and end date of chemotherapy on the association of immune cell profiles and frailty. Thus, all multivariate analyses were repeated controlling for either the number of days between the pre-chemotherapy blood draw and the start of chemotherapy or the number of days between the post-chemotherapy blood draw and the last day of chemotherapy as appropriate.

Analyses were performed using either SAS v. 9.4 (SAS Institute, Cary, NC) or JMP Pro v. 15 (SAS Institute, Cary, NC). $p<0.05$ was used to assess statistical significance.

\section{Results}

Patient and clinical characteristics

A summary of participants' baseline demographic and clinical characteristics is shown in Table 1. All female patients with breast cancer from the primary study were 
Table 1 Baseline demographic and clinical characteristics

\begin{tabular}{|c|c|c|c|c|c|c|}
\hline \multirow[b]{3}{*}{ Total participants: $N=581$} & \multirow[b]{3}{*}{$N=581$} & \multicolumn{5}{|l|}{ Frailty score } \\
\hline & & 0 & 1 & 2 & 3 & 4 \\
\hline & & $N=173$ & $N=195$ & $N=109$ & $N=88$ & $N=16$ \\
\hline \multicolumn{7}{|l|}{ Age, years: $N(\%)$} \\
\hline Mean [range] & $53.4[22-81]$ & $54.3[29-72]$ & $54.3[22-76]$ & $51.7[26-75]$ & $51.3[26-81]$ & $55.75[35-81]$ \\
\hline$<50$ & $205(35.3)$ & $57(32.9)$ & $58(29.7)$ & $46(42.2)$ & $39(44.3)$ & $5(31.3)$ \\
\hline $50-64$ & $284(48.9)$ & $87(50.3)$ & $101(51.8)$ & $49(45.0)$ & $39(44.3)$ & $8(50.0)$ \\
\hline$\geq 65$ & $92(15.8)$ & $29(16.8)$ & $36(18.5)$ & $14(12.8)$ & $10(11.4)$ & $3(18.7)$ \\
\hline \multicolumn{7}{|l|}{ Race: $N$ (\%) } \\
\hline White & $518(89.2)$ & $158(91.3)$ & $178(91.3)$ & $94(86.2)$ & $73(83.0)$ & $15(93.8)$ \\
\hline Non-white & $63(10.8)$ & $15(8.7)$ & $17(8.7)$ & $15(13.8)$ & $15(17.0)$ & $1(6.2)$ \\
\hline \multicolumn{7}{|l|}{ Education: $N(\%)$} \\
\hline High school or below & $142(24.4)$ & $37(21.4)$ & $42(21.5)$ & $30(27.5)$ & $27(30.7)$ & $6(37.5)$ \\
\hline Some college or above & $439(75.6)$ & $136(78.6)$ & $153(78.5)$ & $79(72.5)$ & $61(69.3)$ & $10(62.5)$ \\
\hline \multicolumn{7}{|l|}{ Marital status: $N(\%)$} \\
\hline Married/long-term relationship & $422(72.6)$ & $139(80.3)$ & 139 (71.3) & $71(65.1)$ & $66(75.0)$ & $7(43.8)$ \\
\hline Others & $159(27.4)$ & 34 (19.7) & $56(28.7)$ & $38(34.9)$ & $22(25.0)$ & $9(56.2)$ \\
\hline \multicolumn{7}{|l|}{ Cancer stage: $N(\%)$} \\
\hline 1 & $158(27.2)$ & $50(28.9)$ & $59(30.3)$ & $27(24.8)$ & $18(20.4)$ & $4(25.0)$ \\
\hline$\|$ & $286(49.2)$ & $94(54.3)$ & $85(43.6)$ & $56(51.4)$ & $44(50.0)$ & $7(43.8)$ \\
\hline III & 108 (18.6) & $24(13.9)$ & $42(21.5)$ & $20(18.3)$ & $18(20.5)$ & $4(25.0)$ \\
\hline Unknown & $29(5.0)$ & $5(2.9)$ & $9(4.6)$ & $6(5.5)$ & $8(9.1)$ & $1(6.2)$ \\
\hline \multicolumn{7}{|l|}{ Type of treatment: $N(\%)$} \\
\hline Adjuvant & $481(82.8)$ & $145(83.8)$ & $154(79.0)$ & $92(84.4)$ & $76(86.4)$ & $14(87.5)$ \\
\hline Neoadjuvant & $100(17.2)$ & $28(16.2)$ & $41(21.0)$ & $17(15.6)$ & $12(13.6)$ & $2(12.5)$ \\
\hline \multicolumn{7}{|l|}{ Type of chemotherapy: $N(\%)$} \\
\hline Anthracycline & $278(47.9)$ & $85(49.1)$ & $91(46.7)$ & $57(52.2)$ & $38(43.2)$ & $7(43.8)$ \\
\hline Non-anthracycline & $303(52.1)$ & $88(50.9)$ & $104(53.3)$ & $52(47.8)$ & $50(56.8)$ & $9(56.2)$ \\
\hline \multicolumn{7}{|l|}{ Growth factor: $N(\%)$} \\
\hline Yes & $471(81.1)$ & $147(85.0)$ & $152(77.9)$ & $89(81.7)$ & $70(79.5)$ & $13(81.3)$ \\
\hline No & $110(18.9)$ & $26(15.0)$ & $43(22.1)$ & $20(18.3)$ & $18(20.5)$ & $3(18.7)$ \\
\hline
\end{tabular}

included in the analysis [24, 25]. A total of 581 patients was included in this analysis (Fig. 1). The mean age of the patients was 53.4 (range 22-81; SD 10.6 years). The majority of patients were white $(89.2 \%)$, received some college education (75.6\%), and were married or in a long-term relationship (72.6\%). Eighty-three percent of patients received adjuvant treatment for their cancer and $27.2 \%$ had stage I, $49.2 \%$ had stage II, and $18.6 \%$ had stage III breast cancer. Most patients received growth factors with at least one cycle of treatment $(81.1 \%)$ and $47.9 \%$ were treated with an anthracycline.

The mean frailty score of patients before receiving chemotherapy was 1.3 (SD 1.1; Table 2). The frailty score increased significantly to 2.0 (SD 1.2) postchemotherapy and returned to pre-chemotherapy levels (mean score $=1.3$; SD 1.1) by 6 months post- chemotherapy (Table 2). In post-chemotherapy compared to pre-chemotherapy, patients reported that they were weaker ( $54.3 \%$ vs $25.0 \% ; p<0.001)$, more exhausted $(63.9 \%$ vs $39.7 \% ; p=0.008)$, walked more slowly $(66.6 \%$ vs $54.5 \% ; p<0.001)$, and engaged in less physical activity $(14.3 \%$ vs $9.2 \% ; p=0.008)$ (Table 2). Six months after the completion of chemotherapy, patients were less active (completed $<150 \mathrm{~min} /$ week of physical activity) than they were pre-chemotherapy $(6.0 \%$ vs $9.2 \% ; p=0.049)$ (Table 2). All other components of frailty returned to pre-chemotherapy levels 6 months after the completion of their chemotherapy regimen (Table 2).

Cellular inflammatory markers, frailty, and chemotherapy In pre-chemotherapy compared to post-chemotherapy, there was a significant increase in NLR (3.00 vs 5.03; $p<$ 
Table 2 Difference in frailty and immune cell profiles pre-, post-, and 6 months post-chemotherapy

\begin{tabular}{|c|c|c|c|c|c|}
\hline & $\begin{array}{l}\text { Pre-chemo } N \\
(\%)\end{array}$ & $\begin{array}{l}\text { Post-chemo } N \\
\text { (\%) }\end{array}$ & $\begin{array}{l}6 \text { months post-chemo } N \\
(\%)\end{array}$ & $\begin{array}{l}\text { Pre- vs post-chemo } \\
\text { ( } p \text { value) }\end{array}$ & $\begin{array}{l}\text { Pre- vs } 6 \text { months post-chemo } \\
\text { ( } p \text { value) }\end{array}$ \\
\hline \multicolumn{6}{|l|}{ Frailty components } \\
\hline Weakness $\geq 4$ & $145(25.0)$ & $290(54.3)$ & $153(30.2)$ & $<0.001$ & 0.056 \\
\hline Exhaustion $\geq 4$ & $230(39.7)$ & $342(63.9)$ & $214(42.3)$ & 0.008 & 0.378 \\
\hline Walk speed <2 mph & $313(54.5)$ & $353(66.6)$ & $254(50.7)$ & $<0.001$ & 0.210 \\
\hline $\begin{array}{l}\text { Physical activity < } 150 \mathrm{~min} / \\
\text { week }\end{array}$ & $53(9.2)$ & $76(14.3)$ & $30(6.0)$ & 0.008 & 0.049 \\
\hline \multicolumn{6}{|l|}{ Frailty score: $N(\%)$} \\
\hline 0 & $173(29.8)$ & $74(13.8)$ & $154(30.4)$ & $<0.001$ & 0.480 \\
\hline 1 & $195(33.6)$ & $122(22.8)$ & $151(29.8)$ & & \\
\hline 2 & 109 (18.8) & $124(23.1)$ & $115(22.7)$ & & \\
\hline 3 & $88(15.2)$ & $173(32.3)$ & $74(14.6)$ & & \\
\hline 4 & $16(2.8)$ & $43(8.0)$ & $12(2.37)$ & & \\
\hline Mean [SD] & $1.3[1.1]$ & $2.0[1.2]$ & $1.3[1.1]$ & $<0.001$ & 0.846 \\
\hline \multicolumn{6}{|l|}{ Cell counts: mean [SD] } \\
\hline Neutrophils $\left(10^{3}\right.$ cells/ $\left./ \mathrm{L}\right)$ & $4.69[2.68]$ & $4.84[5.01]$ & - & 0.560 & - \\
\hline Lymphocytes $\left(10^{3}\right.$ cells $\left./ \mu \mathrm{L}\right)$ & $1.88[0.97]$ & $1.22[1.48]$ & - & $<0.0001$ & - \\
\hline Monocytes $\left(10^{3}\right.$ cells/ML) & $0.53[0.55]$ & $0.54[0.53]$ & - & 0.947 & - \\
\hline NLR & $3.00[2.98]$ & $5.03[5.71]$ & - & $<0.001$ & - \\
\hline LMR & $5.72[31.2]$ & $2.8[1.98]$ & - & 0.038 & - \\
\hline Total WBC $\left(10^{3}\right.$ cells/mL) & $7.42[3.05]$ & $6.59[4.76]$ & - & $<0.001$ & - \\
\hline Hemoglobin (g/dL) & $12.67[2.28]$ & $11.12[1.58]$ & - & $<0.001$ & - \\
\hline Hematocrit (\%) & $37.50[6.92]$ & $33.26[4.65]$ & - & $<0.001$ & - \\
\hline Platelets ( $10^{3}$ cells $\left./ \mu \mathrm{L}\right)$ & $260.27[81.82]$ & $237.93[89.16]$ & - & $<0.001$ & - \\
\hline Albumin (g/dL) & $4.17[0.43]$ & $3.93[0.47]$ & - & $<0.001$ & - \\
\hline
\end{tabular}

$S D$ standard deviation, $\mu L$ microliter, $g$ gram, $d L$ deciliter, \% percent, $N L R$ neutrophil to lymphocyte ratio, $L M R$ lymphocyte to monocyte ratio, $W B C$ white blood cell

0.001), with a significant decrease in the mean cell count of lymphocytes (1.88 vs $1.22 ; p<0.001)$, total WBC count (7.42 vs $6.59 ; p<0.001)$, and LMR (5.72 vs 2.80 ; $p=0.038$ ) (Table 2). There was no significant change in levels of neutrophils or monocytes with chemotherapy (Table 2).

In multivariate analyses, total $\mathrm{WBC}(\beta=0.037 ; p<$ $0.05)$, neutrophils $(\beta=0.041 ; p<0.5)$, and NLR $(\beta=$ $0.044 ; p<0.01)$ at the pre-chemotherapy time point were associated with pre-chemotherapy frailty (Table 3 ). We repeated these analyses controlling for the number of days between the pre-chemotherapy blood draw and the start of chemotherapy; we found that these associations remained significant (total WBC $(\beta=0.039 ; p<0.05)$, neutrophils $(\beta=0.39 ; p<0.05)$, and NLR $(\beta=0.041 ; p<$ $0.05)$; Supplementary Table 1) regardless of the timing of the collection of pre-chemotherapy cell counts.

Multivariate analyses also demonstrated that a greater increase (from pre-chemotherapy to post-chemotherapy) in total WBC $(\beta=0.024 ; p<0.05)$, neutrophils $(\beta=0.026$; $p<0.05)$, and NLR $(\beta=0.032 ; p<0.01)$ was associated with frailty at the post-chemotherapy time point (Table 4). Similarly, we repeated these analyses controlling for the number of days between the postchemotherapy blood draw and the last day of chemotherapy; we also found that these associations remained significant (total WBC $(\beta=0.021 ; p<0.05)$, neutrophils $(\beta=0.24 ; p<0.05)$, and NLR $(\beta=0.029 ; p<0.01)$; Supplementary Table 2) regardless of the timing of the collection of post-chemotherapy cell counts.

We next tested the association of cellular markers of inflammation with frailty in the subset of participants who received growth factors with chemotherapy and found that these associations remained significant (total WBC $(\beta=0.023 ; p<0.05)$, neutrophils $(\beta=0.023 ; p<$ $0.05)$, and NLR $(\beta=0.031 ; p<0.01)$; Supplementary Table 3).

In these models, higher pre-chemotherapy frailty and being not being married or in a long-term relationship were predictive of post-chemotherapy frailty. No significant associations were found between pre-chemotherapy cell counts and post-chemotherapy frailty score 
Table 3 Association of pre-chemotherapy cell counts and pre-chemotherapy frailty

\begin{tabular}{|c|c|c|c|c|c|c|}
\hline \multirow{2}{*}{$\begin{array}{l}\text { Pre-chemotherapy } \\
\text { Neutrophils }\end{array}$} & \multicolumn{6}{|c|}{ Pre-chemotherapy frailty score $\beta$ (SE) } \\
\hline & \multicolumn{6}{|l|}{$0.041^{* *}$} \\
\hline & \multicolumn{6}{|l|}{$(0.018)$} \\
\hline \multirow[t]{2}{*}{ Lymphocytes } & & \multicolumn{5}{|l|}{0.043} \\
\hline & & \multicolumn{5}{|l|}{$(0.051)$} \\
\hline \multirow[t]{2}{*}{ Monocytes } & & & \multicolumn{4}{|l|}{0.069} \\
\hline & & & \multicolumn{4}{|l|}{$(0.090)$} \\
\hline \multirow[t]{2}{*}{ NLR } & & & & \multicolumn{3}{|l|}{$0.044^{* * *}$} \\
\hline & & & & \multicolumn{3}{|l|}{$(0.017)$} \\
\hline \multirow[t]{2}{*}{ LMR } & & & & \multicolumn{3}{|c|}{0.001} \\
\hline & & & & \multicolumn{3}{|c|}{$(0.002)$} \\
\hline \multirow[t]{2}{*}{ WBC } & & & & & & $0.037^{* *}$ \\
\hline & & & & & & $(0.015)$ \\
\hline \multirow[t]{2}{*}{ Age 50-64 } & -0.134 & -0.132 & -0.147 & -0.132 & -0.134 & -0.151 \\
\hline & $(0.109)$ & $(0.109)$ & $(0.109)$ & $(0.111)$ & $(0.111)$ & $(0.104)$ \\
\hline \multirow[t]{2}{*}{ Age $65+$} & $-0.298^{*}$ & $-0.289^{*}$ & $-0.281^{*}$ & $-0.276^{*}$ & $-0.275^{*}$ & $-0.270^{*}$ \\
\hline & $(0.153)$ & $(0.154)$ & $(0.153)$ & $(0.156)$ & $(0.155)$ & $(0.146)$ \\
\hline \multirow[t]{2}{*}{ White (yes = 1) } & $-0.272^{*}$ & -0.261 & -0.230 & $-0.313^{*}$ & -0.273 & $-0.256^{*}$ \\
\hline & $(0.162)$ & $(0.162)$ & $(0.160)$ & $(0.165)$ & $(0.167)$ & $(0.153)$ \\
\hline \multirow[t]{2}{*}{ Married (yes = 1) } & $-0.261^{* *}$ & $-0.245^{* *}$ & $-0.250^{* *}$ & $-0.283^{* *}$ & $-0.280^{* *}$ & $-0.248^{* *}$ \\
\hline & $(0.113)$ & $(0.114)$ & $(0.113)$ & $(0.115)$ & $(0.115)$ & $(0.109)$ \\
\hline \multirow[t]{2}{*}{ Some college or above $=1$} & $-0.271^{* *}$ & $-0.226^{*}$ & $-0.233^{* *}$ & $-0.259^{* *}$ & $-0.220^{*}$ & $-0.268^{* *}$ \\
\hline & $(0.116)$ & $(0.116)$ & $(0.116)$ & $(0.118)$ & $(0.118)$ & $(0.110)$ \\
\hline \multirow[t]{2}{*}{ Constant } & $1.846^{* * *}$ & $1.902^{* * *}$ & $1.929^{* * *}$ & $1.955^{* * *}$ & $2.006^{* * *}$ & $1.730^{* * *}$ \\
\hline & $(0.210)$ & $(0.228)$ & $(0.201)$ & $(0.203)$ & $(0.200)$ & $(0.221)$ \\
\hline Observations & 513 & 516 & 517 & 499 & 495 & 553 \\
\hline$R$-squared & 0.043 & 0.032 & 0.031 & 0.047 & 0.033 & 0.044 \\
\hline
\end{tabular}

Linear regression models were used to evaluate the association between cell counts and frailty, controlling for age (below $50,50-64$ versus $\geq 65$ years), race (Caucasian versus others), marital status (married versus others), and education ( $\geq$ some college versus $\leq$ high school)

$N L R$ neutrophil to lymphocyte ratio, $L M R$ lymphocyte to nonocyte ratio

*Significant at $10 \%$; ${ }^{*}$ significant at $5 \%$; ${ }^{* *}$ significant at $1 \%$

(Supplementary Table 4) or in the subset of patients who received growth factors with chemotherapy (Supplementary Table 5). There were also no significant associations between change in cell count from prechemotherapy to post-chemotherapy and 6-month postchemotherapy frailty score (Supplementary Table 6).

\section{Discussion}

In this secondary analysis of data from a nationwide, multi-center longitudinal cohort study, we confirmed the relationships between inflammation and frailty characteristics that have been reported in communitydwelling older adults as well as older adults with cancer over the age of 65 years $[12,14,21]$. Additionally, we demonstrated an association between cellular markers of inflammation and chemotherapy-induced frailty characteristics. We showed that a greater increase in neutrophils, NLR, and total WBC from prechemotherapy to post-chemotherapy was positively associated with frailty characteristics at the postchemotherapy time point. Moreover, we demonstrated that these associations were not affected by the receipt of growth factors with chemotherapy or by the time between when the laboratory data was obtained and the start or end of chemotherapy. In this cohort of patients, we found that in women with breast cancer undergoing chemotherapy, frailty increased from pre-chemotherapy to post-chemotherapy and returned to prechemotherapy levels by 6 months after the completion of chemotherapy. To our knowledge, this is the first study to investigate the predictive effect of cellular markers of inflammation using laboratory data on frailty characteristics that are associated with chemotherapy. 
Table 4 Association of change in cell counts (pre- to post-chemotherapy) and with post-chemotherapy frailty

\begin{tabular}{|c|c|c|c|c|c|c|}
\hline \multirow{2}{*}{$\begin{array}{l}\text { Change in cell counts } \\
\text { Neutrophils }\end{array}$} & \multicolumn{6}{|c|}{ Post-chemotherapy frailty score: $\beta$ (SE) } \\
\hline & \multicolumn{6}{|l|}{$0.026^{* *}$} \\
\hline & \multicolumn{6}{|l|}{$(0.010)$} \\
\hline \multirow[t]{2}{*}{ Lymphocytes } & & \multicolumn{5}{|l|}{0.042} \\
\hline & & \multicolumn{5}{|l|}{$(0.032)$} \\
\hline \multirow[t]{2}{*}{ Monocytes } & & & \multicolumn{4}{|l|}{0.019} \\
\hline & & & \multicolumn{4}{|l|}{$(0.074)$} \\
\hline \multirow[t]{2}{*}{ NLR } & & & & \multicolumn{3}{|l|}{$0.032^{* * *}$} \\
\hline & & & & \multicolumn{3}{|l|}{$(0.009)$} \\
\hline \multirow[t]{2}{*}{ LMR } & & & & \multicolumn{3}{|c|}{$-0.003^{*}$} \\
\hline & & & & \multicolumn{3}{|c|}{$(0.002)$} \\
\hline \multirow[t]{2}{*}{ WBC } & & & & & & $0.024 * *$ \\
\hline & & & & & & $(0.009)$ \\
\hline \multirow[t]{2}{*}{ Baseline frailty } & $0.318^{* * *}$ & $0.312^{* * *}$ & $0.308^{* * *}$ & $0.332^{* * *}$ & $0.321^{* * *}$ & $0.297^{* * *}$ \\
\hline & $(0.046)$ & $(0.047)$ & $(0.047)$ & $(0.047)$ & $(0.048)$ & $(0.045)$ \\
\hline \multirow[t]{2}{*}{ Age 50-64 } & $0.216^{*}$ & $0.224^{*}$ & $0.215^{*}$ & $0.210^{*}$ & $0.211^{*}$ & $0.212^{*}$ \\
\hline & $(0.115)$ & $(0.115)$ & $(0.115)$ & $(0.116)$ & $(0.119)$ & $(0.111)$ \\
\hline \multirow[t]{2}{*}{ Age $65+$} & $0.312^{*}$ & $0.323^{* *}$ & $0.301^{*}$ & 0.270 & $0.332^{* *}$ & 0.240 \\
\hline & $(0.160)$ & $(0.161)$ & $(0.161)$ & $(0.164)$ & $(0.167)$ & $(0.156)$ \\
\hline \multirow[t]{2}{*}{ White (yes = 1) } & 0.104 & 0.145 & 0.083 & 0.091 & 0.143 & 0.036 \\
\hline & $(0.176)$ & $(0.177)$ & $(0.174)$ & $(0.179)$ & $(0.183)$ & $(0.169)$ \\
\hline \multirow[t]{2}{*}{ Married (yes $=1$ ) } & $-0.331^{* * *}$ & $-0.322^{* * *}$ & $-0.328^{* * *}$ & $-0.281^{* *}$ & $-0.268^{* *}$ & $-0.311^{* * *}$ \\
\hline & $(0.118)$ & $(0.120)$ & $(0.120)$ & $(0.121)$ & $(0.124)$ & $(0.116)$ \\
\hline \multirow[t]{2}{*}{ Some college or above $=1$} & 0.152 & 0.136 & 0.113 & 0.204 & 0.143 & 0.185 \\
\hline & $(0.123)$ & $(0.123)$ & $(0.123)$ & $(0.125)$ & $(0.127)$ & $(0.118)$ \\
\hline \multirow[t]{2}{*}{ Constant } & $1.444^{* * *}$ & $1.462^{* * *}$ & $1.520^{* * *}$ & $1.296^{* * *}$ & $1.350^{* * *}$ & $1.564^{* * *}$ \\
\hline & $(0.230)$ & $(0.233)$ & $(0.228)$ & $(0.236)$ & $(0.239)$ & $(0.223)$ \\
\hline Observations & 459 & 459 & 461 & 439 & 427 & 508 \\
\hline$R$-squared & 0.135 & 0.123 & 0.115 & 0.147 & 0.126 & 0.115 \\
\hline
\end{tabular}

Linear regression models were used to evaluate the association between cell counts and frailty, controlling for age (below 50, 50-64 versus $\geq 65$ years), race (white versus non-white), marital status (married/long term relationship versus others), and education ( $\geq$ some college versus $\leq$ high school)

$N L R$ neutrophil to lymphocyte ratio, $L M R$ lymphocyte to monocyte ratio

*Significant at $10 \% ;{ }^{* *}$ significant at $5 \%$; ${ }^{* * *}$ significant at $1 \%$

Chronic low-grade inflammation (i.e., subclinical inflammation) is independently associated with frailty. Leukocytes are an essential component of the immune system and consist of neutrophils, eosinophils, and basophils (that comprise the granulocytic component) as well as lymphocytes and monocytes (that comprise the non-granulocytic component). Neutrophils are the most abundant granulocytic leukocyte and have traditionally been thought of as the first line of defense against infections. However, recent studies have shown that neutrophils also play a vital role in chronic inflammatory responses in immunological diseases such as cancer by interacting with other immune cells such as lymphocytes [29]. We have shown that in patients with breast cancer, the level of neutrophils in peripheral blood is independently associated with frailty characteristics prior to receiving chemotherapy.

While no significant changes were observed in the levels of neutrophils and monocytes from prechemotherapy to post-chemotherapy, there were significant changes in the concentration of WBC, lymphocytes, NLR, LMR, hemoglobin, hematocrit, platelets, and albumin. However, it is important to emphasize that these changes remained within the laboratory-referenced normal range. Given that these tests were completed within 1 month of completing chemotherapy and that the values remained within the normal ranges suggests that the hematopoietic systems of these patients recovered after chemotherapy. 
Notably, even though there were subtle and nonsignificant changes within the normal range of neutrophil concentration from pre-chemotherapy to postchemotherapy, we found that an increase in neutrophils from pre-chemotherapy to post-chemotherapy was associated with frailty at the post-chemotherapy time point, after controlling for the pre-chemotherapy frailty score. These findings suggest that subclinical changes (changes within the normal range) are important to consider when making treatment decisions based on the effect of cancer treatment on frailty in patients with breast cancer.

Along with neutrophilic responses, NLR is also commonly used as a marker of subclinical inflammation. NLR can signify an imbalance between various components of the immune system, with higher neutrophils indicating an activation of the pro-inflammatory immune pathways and lower lymphocytes reflecting depressed cellular immunity [11]. In fact, in patients with breast cancer, an elevated NLR has been associated with poor prognosis [30, 31]. The observed independent association of NLR with frailty suggests that low-grade inflammation as well as subclinical changes in inflammation is a prognostic factor for frailty in patients with breast cancer. Unfortunately, the mechanism underlying the contribution of NLR to poor outcomes including frailty is unknown. Emerging evidence indicates that the roles of neutrophils are more complex than previously thought. In patients with cancer, neutrophils can be polarized to exhibit different phenotypes depending on which tumorderived factors as well as other immune cells interact with them. As a result, in patients with cancer, neutrophils can have either immunostimulating or immunosuppressive properties. Immunostimulating neutrophils, also known as anti-tumorigenic neutrophils, can activate cytotoxic CD8+ $\mathrm{T}$ cells (a subset of lymphocytes) to exert immunostimulating effects $[29,32]$. On the other hand, in patients with cancer, neutrophils have been shown to exert immunosuppressive properties [33, 34]. More work is needed to clarify the varying roles of neutrophil subsets as well as the ratios of different leukocyte subsets as immunological biomarkers that may predict frailty and frailty trajectories in patients with breast cancer.

A recent study by Bailur et al. aimed to elucidate the association of distinct immune subsets with frailty through the use of immunoprofiling flow cytometry techniques. These authors showed that in older adults with breast cancer, patients with higher prechemotherapy levels of granulocytic cells but lower levels of myeloid-suppressor cells and regulatory $\mathrm{T}$ cells were more frail prior to initiating chemotherapy [35]. While no association was found between prechemotherapy immune subsets and frailty (assessed using the geriatric assessment) at 3 and 12 months after starting chemotherapy, these profiles were predictive of unexpected hospitalizations. Our study had complementary findings; we demonstrated that neutrophils, which make up a major component of the granulocytic immune component, were associated with frailty in patients with cancer. While Bailur et al. found no association between immune cell profiles and frailty after chemotherapy, we found that changes to the neutrophil component following chemotherapy were independently associated with post-chemotherapy frailty but not with frailty 6 months after completing chemotherapy. These differences in findings may be multifactorial. Firstly, participants in our study were younger (mean age 53 vs 73 ). Secondly, there were differences in the timing of blood draws for the post-chemotherapy time point (within 4 weeks after the last chemotherapy cycle (mean 18.4 $(\mathrm{SD}=24.3)$ days $)$ vs on the day of the last cycle of chemotherapy). Thirdly, in the current study, we examined the association between longitudinal changes in cellular markers of inflammation over the course of treatment and frailty. Nevertheless, the study by Bailur et al. indicates that chemotherapy has varying effects on different cell subsets within the immune system. Thus, when assessing the role of immune cell components on clinical outcomes of patients with cancer in the context of chemotherapy, the change of each immune subset should be carefully monitored. Together our current study along with that of Bailur et al. sheds light on the complexity of immunological biomarkers as predictors of frailty. Future studies evaluating the value of immune cell subsets as biomarkers to predict frailty should consider immunoprofiling techniques, where the individual contributions of distinct immune subsets (e.g., immunostimulating vs immunosuppressive neutrophils) are evaluated for their association with chemotherapyinduced frailty.

Interestingly, while the changes in neutrophils and NLR were associated with post-chemotherapy frailty as well as change in frailty from pre-chemotherapy to postchemotherapy, they were not predictive of frailty 6 months after completing chemotherapy. This suggests that while immune cell counts might be valuable in providing information to assist oncologists in making decisions about acute frailty, these immune profiles might not be predictive of chronic chemotherapy-induced frailty in patients with breast cancer.

Although frailty is typically characterized as an agingrelated condition, it is important to recognize that frailty also exists in younger patients, especially in the context of cancer $[3,36]$. It has been demonstrated that childhood survivors of cancer are more frail than their agedmatched non-cancer counterparts, and they exhibit features of accelerated aging [3]. Cancer contributes to 
biological changes across varying domains that result in an overall dysregulation of energy systems. This dysregulation has clinical manifestations such as weakness, exhaustion, low physical activity, slow walking speed, and weight loss which ultimately constitutes the frailty phenotype $[4,37]$. Thus, in patients with cancer, frailty is a stronger predictor than age of negative cancer treatment outcomes such as post-operative outcomes, chemotherapy-related toxicities, unexpected hospitalizations, morbidity, and mortality [2]. In our cohort, we found that patients with breast cancer with a mean age of 53 years were already exhibiting frailty characteristics prior to starting chemotherapy, with about $40 \%$ of patients having more than two frailty characteristics before the first chemotherapy cycle (Table 2). Thus, when treating patients with breast cancer, oncologists should consider the effect of chemotherapy on frailty on all patients, both those younger and older than 65 years of age.

This study had several strengths. First, even though this was a younger cohort (mean age 53 years), we were able to replicate the findings of multiple studies on the association between cellular markers of inflammation and frailty. In addition, this study used available data from a cohort study that enrolled participants from multiple community oncology sites within the USA, making our findings generalizable to patients seen in oncology clinics within community settings that traditionally treat the majority of patients with cancer. Third, this was a large $(n=581)$ longitudinal study with measures obtained at multiple time points, allowing us to observe longitudinal changes in the cellular markers of inflammation as well as changes in frailty.

Our study also has limitations. We utilized a modified Fried's frailty score due to the inability to measure unintentional weight loss. However, even with the use of the modified frailty criteria, we were able to corroborate previous findings of an association between inflammation and frailty. Given the complexity of the components and functions of the immune system, future work evaluating the role of cellular markers of inflammation on chronic chemotherapy-induced frailty should use immunoprofiling techniques, such as multiplex immunofluorescence, genomics, and/or proteomics.

\section{Conclusions}

In patients with breast cancer receiving chemotherapy, cellular markers of inflammation are associated with acute but not persistent frailty. Immune cell counts may help clinicians identify patients at risk of frailty during chemotherapy. Additional research is needed to understand how changes in these immune cell profiles contribute to frailty and to determine the individual contributions of specific immune subsets.

\section{Supplementary Information}

The online version contains supplementary material available at https://doi. org/10.1186/s13058-021-01388-w.

Additional file 1: Table S1. Association of Pre-Chemotherapy Cell Counts with Pre-Chemotherapy Frailty also controlling for the number of days between pre-chemotherapy lab draw and start of chemotherapy. Table S2. Association of Change in Cell Counts (Pre to Post-

Chemotherapy) with Post-Chemotherapy Frailty also controlling for the number of days between post-chemotherapy lab draw and end of chemotherapy. Table S3. Association of Change in Cell Counts (Pre to Post-Chemotherapy) with Post-Chemotherapy Frailty in patients who received growth factor with chemotherapy. Table S4. Association of PreChemotherapy Cell Counts with Frailty at Post-Chemotherapy and 6 Month Post-Chemotherapy Time-Points in Patients with Breast Cancer. Table S5. Association of Pre-Chemotherapy Cell Counts with Frailty at Post-Chemotherapy and 6 Month Post-Chemotherapy Time-Points in Patients with Breast Cancer in patients who received growth factor with chemotherapy. Table S6. Association of Change in Cell Counts (Pre to Post-Chemotherapy) with 6-Month Post-Chemotherapy Frailty.

\section{Acknowledgements}

We wish to acknowledge Drs. Susan Rosenthal for her editorial assistance. We will also like to thank Elizabeth Nagalski, Scarlett Montanaro, and Jacque Lindke for their tremendous assistance with the careful review of the charts of all enrolled subjects to capture the data needed for this manuscript. The project described in this publication was supported by the University of Rochester CTSA award number KL2TR001999 from the National Center for Advancing Translational Sciences of the National Institutes of Health. The content is solely the responsibility of the authors and does not necessarily represent the official views of the National Institutes of Health.

\section{Authors' contributions}

NG, SG, and MJ conceived and designed the study. MJ is the Principal Investigator of the URCC 10055 study and provided all of the study materials. $A C, L W$, and $M O$ coordinated study materials and participants. NG, LL, and EC performed the data and statistical analyses and prepared all tables and figures. NG, SM, LL, EC, MM, AM, KPL, RM, EB, and MJ interpreted all study results pertaining to immune cell profiles and frailty in patients with breast cancer receiving chemotherapy. NG drafted the manuscript and all authors contributed to revisions. All authors read and approved the final manuscript.

\section{Funding}

This work was supported by the University of Rochester CTSA award No. KL2TR001999, the National Cancer Institute Grant Nos. U10CA037420, K07CA1688, T32CA102618, UG1CA18996, DP2195765, K24AG056589, and K99CA237744, National Institute on Aging Grant No. K76 AG064394, and the Wilmot Cancer Research Fellowship.

Availability of data and materials

Data may be available upon request.

Ethics approval and consent to participate

Institutional review boards at the URCC NCORP Research Base and each of the NCORP Community Affiliates approved the study.

\section{Consent for publication}

This manuscript does not contain any individual person's data in any form.

\section{Competing interests}

The authors have no relevant conflicts of interest to report.

\section{Author details}

${ }^{1}$ Cancer Control, University of Rochester School of Medicine and Dentistry, Rochester, New York, USA. ${ }^{2}$ James P. Wilmot Cancer Institute, University of Rochester School of Medicine and Dentistry, Rochester, New York, USA.

${ }^{3}$ Department of Psychiatry, University of Michigan, Ann Arbor, Michigan, USA.

${ }^{4}$ Pacific Cancer Research Consortium NCORP, Providence Cancer Institute

Franz Clinic, Portland, Oregon, USA. ${ }^{5}$ Northwell Health NCORP, The Monter 
Cancer Center, Lake Success, New York, USA. ${ }^{6}$ Dayton Clinical Oncology Program, Dayton, Ohio, USA.

Received: 29 June 2020 Accepted: 5 January 2021

Published online: 05 February 2021

\section{References}

1. DeSantis CE, Ma J, Gaudet MM, Newman LA, Miller KD, Goding Sauer A, et al. Breast cancer statistics, 2019. CA Cancer J Clin. 2019;69(6):438-51.

2. Ethun CG, Bilen MA, Jani AB, Maithel SK, Ogan K, Master VA. Frailty and cancer: implications for oncology surgery, medical oncology, and radiation oncology. CA Cancer J Clin. 2017;67(5):362-77.

3. Hayek S, Gibson TM, Leisenring WM, Guida JL, Gramatges MM, Lupo PJ, et al. Prevalence and predictors of frailty in childhood cancer survivors and siblings: a report from the childhood cancer survivor study. I Clin Oncol. 2020;38(3):232-47.

4. Fried LP, Tangen CM, Walston J, Newman AB, Hirsch C, Gottdiener J, et al. Frailty in older adults: evidence for a phenotype. J Gerontol A Biol Sci Med Sci. 2001;56(3):M146-56.

5. Rockwood K, Stadnyk K, MacKnight C, McDowell I, Hebert R, Hogan DB. A brief clinical instrument to classify frailty in elderly people. Lancet. 1999; 353(9148):205-6.

6. Alencar MA, Dias JM, Figueiredo LC, Dias RC. Frailty and cognitive impairment among community-dwelling elderly. Arq Neuropsiquiatr. 2013; 71(6):362-7.

7. Kojima G, lliffe S, Morris RW, Taniguchi Y, Kendrick D, Skelton DA, et al, Frailty predicts trajectories of quality of life over time among British community-dwelling older people. Qual Life Res. 2016;25(7):1743-50.

8. Mandelblatt JS, Cai L, Luta G, Kimmick G, Clapp J, Isaacs C, et al. Frailty and long-term mortality of older breast cancer patients: CALGB 369901 (Alliance). Breast Cancer Res Treat. 2017;164(1):107-17.

9. Williams GR, Deal AM, Sanoff HK, Nyrop KA, Guerard EJ, Pergolotti M, et al. Frailty and health-related quality of life in older women with breast cancer. Support Care Cancer. 2019;27(7):2693-8.

10. Walker KA, Walston J, Gottesman RF, Kucharska-Newton A, Palta P, Windham BG. Midlife systemic inflammation is associated with frailty in later life: the ARIC study. J Gerontol a-Biol. 2019;74(3):343-9.

11. Faria SS, Fernandes $P C \mathrm{Jr}$, Silva MJ, Lima VC, Fontes W, Freitas-Junior R, et al. The neutrophil-to-lymphocyte ratio: a narrative review. Ecancermedicalscience. 2016;10:702.

12. Nishijima TF, Muss HB, Shachar SS, Tamura K, Takamatsu Y. Prognostic value of lymphocyte-to-monocyte ratio in patients with solid tumors: a systematic review and meta-analysis. Cancer Treat Rev. 2015;41(10):971-8.

13. Leng $S X$, Xue QL, Tian J, Walston JD, Fried LP. Inflammation and frailty in older women. J Am Geriatr Soc. 2007:55(6):864-71.

14. Leng SX, Xue QL, Tian J, Huang Y, Yeh SH, Fried LP. Associations of neutrophil and monocyte counts with frailty in community-dwelling disabled older women: results from the Women's Health and Aging Studies I. Exp Gerontol. 2009:44(8):511-6.

15. Nishijima TF, Deal AM, Williams GR, Guerard EJ, Nyrop KA, Muss HB. Frailty and inflammatory markers in older adults with cancer. Aging (Albany NY). 2017;9(3):650-64.

16. Lee $\mathrm{YY}$, Choi $\mathrm{CH}$, Sung $\mathrm{CO}$, Do IG, Huh $\mathrm{S}$, Song $\mathrm{T}$, et al. Prognostic value of pre-treatment circulating monocyte count in patients with cervical cancer: comparison with SCC-Ag level. Gynecol Oncol. 2012;124(1):92-7.

17. Su Z, Mao YP, OuYang PY, Tang J, Xie FY. Initial hyperleukocytosis and neutrophilia in nasopharyngeal carcinoma: incidence and prognostic impact. PLoS One. 2015;10(9):e0136752.

18. Ray-Coquard I, Cropet C, Van Glabbeke M, Sebban C, Le Cesne A, Judson I. et al. Lymphopenia as a prognostic factor for overall survival in advanced carcinomas, sarcomas, and lymphomas. Cancer Res. 2009:69(13):5383-91.

19. Puzianowska-Kuznicka M, Owczarz M, Wieczorowska-Tobis K, Nadrowski P, Chudek J, Slusarczyk P, et al. Interleukin-6 and C-reactive protein, successful aging, and mortality: the PolSenior study. Immun Ageing. 2016;13:21.

20. Van Epps P, Oswald D, Higgins PA, Hornick TR, Aung H, Banks RE, et al. Frailty has a stronger association with inflammation than age in older veterans. Immun Ageing. 2016;13:27.

21. Samson LD, Boots AMH, Verschuren WMM, Picavet HSJ, Engelfriet $P$, Buisman AM. Frailty is associated with elevated CRP trajectories and higher numbers of neutrophils and monocytes. Exp Gerontol. 2019;125:407-15.
22. Kaneko M, Nozawa H, Sasaki K, Hongo K, Hiyoshi M, Tada N, et al. Elevated neutrophil to lymphocyte ratio predicts poor prognosis in advanced colorectal cancer patients receiving oxaliplatin-based chemotherapy. Oncology. 2012;82(5):261-8.

23. Templeton AJ, McNamara MG, Seruga B, Vera-Badillo FE, Aneja P, Ocana A, et al. Prognostic role of neutrophil-to-lymphocyte ratio in solid tumors: a systematic review and meta-analysis. J Natl Cancer Inst. 2014;106(6):dju124.

24. Janelsins MC, Heckler CE, Peppone LJ, Ahles TA, Mohile SG, Mustian KM, et al. Longitudinal trajectory and characterization of cancer-related cognitive impairment in a nationwide cohort study. J Clin Oncol. 2018;36(32): JCO2018786624.

25. Janelsins MC, Heckler CE, Peppone LJ, Kamen C, Mustian KM, Mohile SG, et al. Cognitive complaints in survivors of breast cancer after chemotherapy compared with age-matched controls: an analysis from a nationwide, multicenter, prospective longitudinal study. J Clin Oncol. 2017:35(5):506-14.

26. Gilmore N, Kadambi S, Lei L, Loh KP, Mohamed M, Magnuson A, Cole S, Esparaz BT, Giguere JK, Mohile $S$ et al: Associations of inflammation with frailty in patients with breast cancer aged 50 and over receiving chemotherapy. J Geriatr Oncol 2020;11(3):423-30.

27. Magnuson A, Lei L, Gilmore N, Kleckner AS, Lin FV, Ferguson R, et al. Longitudinal relationship between frailty and cognition in patients 50 years and older with breast cancer. J Am Geriatr Soc. 2019:67(5):928-36.

28. Stofan JR, DiPietro L, Davis D, Kohl HW 3rd, Blair SN. Physical activity patterns associated with cardiorespiratory fitness and reduced mortality: the Aerobics Center Longitudinal Study. Am J Public Health. 1998;88(12):1807-13.

29. Coffelt SB, Wellenstein MD, de Visser KE. Neutrophils in cancer: neutral no more. Nat Rev Cancer. 2016;16(7):431-46.

30. Dirican A, Kucukzeybek BB, Alacacioglu A, Kucukzeybek Y, Erten C, Varol U, et al. Do the derived neutrophil to lymphocyte ratio and the neutrophil to lymphocyte ratio predict prognosis in breast cancer? Int J Clin Oncol. 2015; 20(1):70-81.

31. Guo W, Lu X, Liu Q, Zhang T, Li P, Qiao W, et al. Prognostic value of neutrophil-to-lymphocyte ratio and platelet-to-lymphocyte ratio for breast cancer patients: an updated meta-analysis of 17079 individuals. Cancer Med. 2019;8(9):4135-48.

32. Fridlender ZG, Albelda SM. Tumor-associated neutrophils: friend or foe? Carcinogenesis. 2012:33(5):949-55.

33. Masucci MT, Minopoli M, Carriero MV. Tumor associated neutrophils. Their role in tumorigenesis, metastasis, prognosis and therapy. Front Oncol. 2019;9:1146.

34. Wang $X$, Qiu L, Li Z, Wang XY, Yi H. Understanding the multifaceted role of neutrophils in cancer and autoimmune diseases. Front Immunol. 2018:9:2456.

35. Bailur JK, Pawelec G, Hatse S, Brouwers B, Smeets A, Neven P, et al. Immune profiles of elderly breast cancer patients are altered by chemotherapy and relate to clinical frailty. Breast Cancer Res. 2017;19(1):20.

36. Henderson TO, Ness KK, Cohen HJ. Accelerated aging among cancer survivors: from pediatrics to geriatrics. Am Soc Clin Oncol Educ Book. 2014:e423-30. https:/ascopubs.org/doi/pdf/10.1200/EDBK_156160.

37. Fried LP, Hadley EC, Walston JD, Newman AB, Guralnik JM, Studenski $S$, et al. From bedside to bench: research agenda for frailty. Sci Aging Knowl Environ. 2005;2005(31):pe24.

\section{Publisher's Note}

Springer Nature remains neutral with regard to jurisdictional claims in published maps and institutional affiliations.

Ready to submit your research? Choose BMC and benefit from:

- fast, convenient online submission

- thorough peer review by experienced researchers in your field

- rapid publication on acceptance

- support for research data, including large and complex data types

- gold Open Access which fosters wider collaboration and increased citations

- maximum visibility for your research: over $100 \mathrm{M}$ website views per year

At BMC, research is always in progress.

Learn more biomedcentral.com/submission 